\title{
The influence of nitric acid on the cloud processing of aerosol particles
}

\author{
S. Romakkaniemi ${ }^{1,}{ }^{*}$, H. Kokkola ${ }^{2}$, K. E. J. Lehtinen ${ }^{2}$, and A. Laaksonen ${ }^{1}$ \\ ${ }^{1}$ Department of Applied Physics, University of Kuopio, P.O. BOX 1627, FIN-70211 Kuopio, Finland \\ ${ }^{2}$ University of Kuopio and Finnish Meteorological Institute, Department of Applied Physics, P.O. BOX 1627, FIN-70211 \\ Kuopio, Finland \\ *now at: School of Earth, Atmospheric and Environmental Sciences, University of Manchester, P.O. BOX 88, Manchester \\ M60 1QD, UK
}

Received: 14 September 2005 - Published in Atmos. Chem. Phys. Discuss.: 20 October 2005

Revised: 9 March 2006 - Accepted: 16 March 2006 - Published: 19 May 2006

\begin{abstract}
In this paper we present simulations of the effect of nitric acid $\left(\mathrm{HNO}_{3}\right)$ on cloud processing of aerosol particles. Sulfuric acid $\left(\mathrm{H}_{2} \mathrm{SO}_{4}\right)$ production and incloud coagulation are both affected by condensed nitric acid as nitric acid increases the number of cloud droplets, which will lead to smaller mean size and higher total surface area of droplets. As a result of increased cloud droplet number concentration (CDNC), the incloud coagulation rate is enhanced by a factor of $1-1.3$, so that the number of interstitial particles reduces faster. In addition, sulfuric acid production occurs in smaller particles and so the cloud processed aerosol size distribution is dependent on the $\mathrm{HNO}_{3}$ concentration. This affects both radiative properties of aerosol particles and the formation of cloud droplets during a sequence of cloud formationevaporation events. It is shown that although the condensation of $\mathrm{HNO}_{3}$ increases the number of cloud droplets during the single updraft, it is possible that presence of $\mathrm{HNO}_{3}$ can actually decrease the cloud droplet number concentration after several cloud cycles when also $\mathrm{H}_{2} \mathrm{SO}_{4}$ production is taken into account.
\end{abstract}

\section{Introduction}

Cloud processing, both physical and chemical, is known to efficiently shape aerosol particle size distributions (Hoppel et al., 1994). Cloud droplets grow by condensation of different gases and by coagulation with other cloud droplets and interstitial particles. Volatility of condensed substances may change due to liquid phase chemistry. For example the oxidation of sulfur dioxide $\left(\mathrm{SO}_{2}\right)$ produces $\mathrm{H}_{2} \mathrm{SO}_{4}$ and the hydrolysis of $\mathrm{N}_{2} \mathrm{O}_{5}$ produces $\mathrm{HNO}_{3}$ (see e.g. Seinfeld and Pandis,

Correspondence to: S. Romakkaniemi

(sami.romakkaniemi@manchester.ac.uk)
1998). Most of sulfuric acid and some of nitric acid (depending on the conditions, for example the amount of ammonia present) will stay in the particles also when cloud droplets evaporate. Hence the dry particle size distribution and the chemical composition are altered by chemical processes. This will change the radiative properties of the aerosols (Yuskiewicz et al., 1999; Hegg et al., 2004) and it also affects the number of cloud condensation nuclei (CCN) (Bower and Choularton, 1993; Feingold and Kreidenweis, 2000). Coagulation decreases the number concentration of both interstitial particles and cloud droplets. The mean size of cloud droplets increases and some of the cloud droplets grow big enough to form precipitation. Coagulation processes are also important in nonprecipitating clouds. Nucleation mode particles coagulate rapidly with cloud droplets and also the number of Aitken mode particles decreases rapidly compared to cloud free conditions. As a consequence, the radiative properties of aerosols as well as the properties of clouds during the next cloud cycle are modified.

Previous cloud model studies have shown that trace gases like $\mathrm{HNO}_{3}$ and ammonia $\left(\mathrm{NH}_{3}\right)$ can increase cloud droplet number concentrations significantly (Kulmala et al., 1993; Hegg, 2000; Romakkaniemi et al., 2005; Xue and Feingold, 2004). This will reduce the mean cloud droplet size and thus increase cloud albedo and reduce precipitation efficiency, which increases cloud lifetime. Overall this will lead to a cooling of the lower troposphere and thus the effect is opposite in sign to the warming effect of greenhouse gases. Previously, the effect of $\mathrm{HNO}_{3}$ on precipitation formation has been studied by Roelofs and Jongen (2004). They found that at low updraft velocities rain formation is delayed. Xue and Feingold (2004) found that the condensation of $\mathrm{HNO}_{3}$ broadens the cloud droplet distribution and this should also be taken into account when estimating cloud optical properties.

Published by Copernicus GmbH on behalf of the European Geosciences Union. 
Table 1. Trimodal distribution used in simulation. Particles are supposed to be internally mixed. In continental distribution $50 \%$ of mass is insoluble.

\begin{tabular}{cccc}
\hline CONTINENTAL & \multicolumn{2}{c}{ mode 1} & \multicolumn{2}{c}{ mode 2} & mode 3 \\
composition & \multicolumn{2}{c}{$\left(\mathrm{NH}_{4}\right)_{2} \mathrm{SO}_{4} /$ insoluble } \\
$N\left[\mathrm{~cm}^{-3}\right]$ & 1000 & 800 & 0.72 \\
$r_{g}[\mathrm{~nm}]$ & 8.0 & 34 & 460 \\
$\sigma$ & 1.60 & 2.16 & 2.20 \\
\hline MARINE & mode $1^{2}$ & mode $2^{2}$ & mode 3 \\
composition & $\mathrm{NH}_{4} \mathrm{HSO}_{4}$ & $\mathrm{NaCl}$ \\
$N\left[\mathrm{~cm}^{-3}\right]$ & 340 & 60 & 3.1 \\
$r_{g}[\mathrm{~nm}]$ & 5.0 & 35 & 310 \\
$\sigma$ & 1.60 & 2.00 & 2.70 \\
\hline RURAL & mode 1 & mode 2 & mode 3 \\
composition & \multicolumn{4}{c}{$\left(\mathrm{NH}_{4}\right)_{2} \mathrm{SO}_{4}$} \\
$N\left[\mathrm{~cm}{ }^{-3}\right]$ & 10000 & 147 & 2000 \\
$r_{g}[\mathrm{~nm}]$ & 7.5 & 27 & 42 \\
$\sigma$ & 1.30 & 1.75 & 1.30 \\
\hline
\end{tabular}

$\mathrm{HNO}_{3}$ affects also the cloud processing of aerosol particles. Increased droplet number and decreased size change the rate of droplet-droplet collisions and also the coagulation rate between droplets and interstitial particles changes. Furthermore, the $\mathrm{H}_{2} \mathrm{SO}_{4}$ production occurring in clouds is modified, as $\mathrm{HNO}_{3}$ induces a higher droplet concentration so that the number of particles in the accumulation mode present after cloud evaporation may increase. As a consequence of coagulation and liquid phase chemistry, the cloud droplet number concentration and cloud properties are modified during the forthcoming cloud cycles. Also the radiative properties of aerosol particles can be changed. In order to be able to estimate what is the effect of condensable trace gases on the global radiative forcing the possible importance of these effects need to be explored.

In this study we present cloud model results on the effects of nitric acid on the formation of sulfuric acid and incloud scavenging of aerosol particles. We use a highly accurate air parcel model including differential equations for relevant physical and chemical processes. Due to the limitation of the modelling framework, we can not model the gravitational settling of drizzle limiting the study to nonprecipitating clouds.

\section{Model}

We apply an air parcel model with a moving sectional representation of the evolution of the aerosol size distribution to simulate the $\mathrm{CCN}$ activation to cloud droplets and dynamics of interstitial particles and cloud droplets in adiabatic cloud parcels. Included in the model are differential equations describing condensation, evaporation, coagulation,

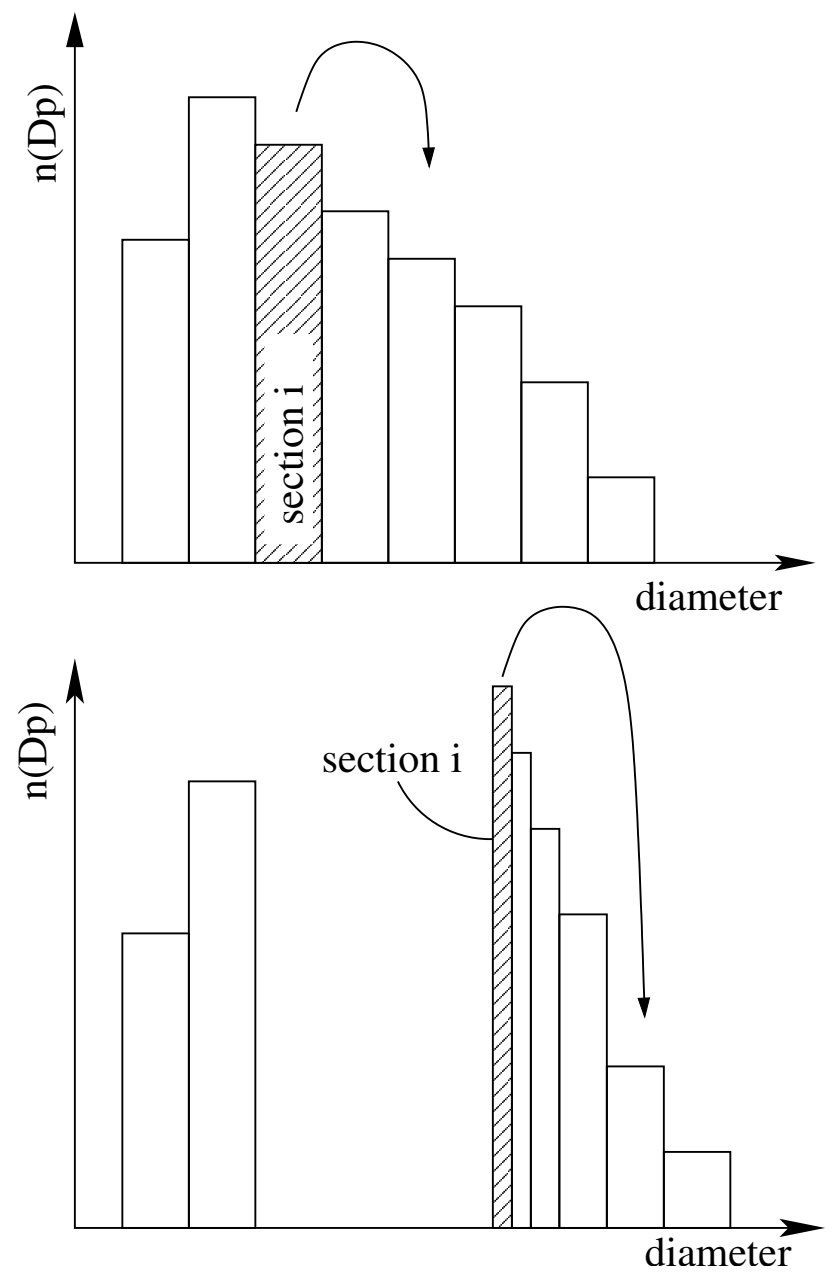

Fig. 1. Illustration of the coagulation of two particles in section $i$ in a moving sectional representation of aerosol size distirbution. Upper panel: Below cloud conditions. Lower panel: Incloud conditions.

chemical reactions in the liquid and gas phases, adiabatic variables and the emissions of gas phase species. The model, excluding the coagulation module, has been described elsewhere (Kokkola, 2003), and so the model is described here only shortly. The differential equations are solved using odesolver DLSODE (www.netlib.org), which solves initial-value problems for stiff or non-stiff ordinary differential equations using backward differentiation formulae.

The liquid phase thermodynamics and initial equilibration are calculated with a modified version of EQUISOLV II, which is a chemical equilibrium code developed by Jacobson (1999). The original EQUISOLV II uses the ZdanovskiiStokes-Robinson (ZSR) method to estimate the liquid water content. This method is not very good for dilute solutions. For our purpose, it is changed so that the water activity is calculated with the method presented by Bromley (1973). The original and modified versions of EQUISOLV II showed a good consistency at $R H$ 's between 90 and $98 \%$ (Kokkola et al., 2003). 

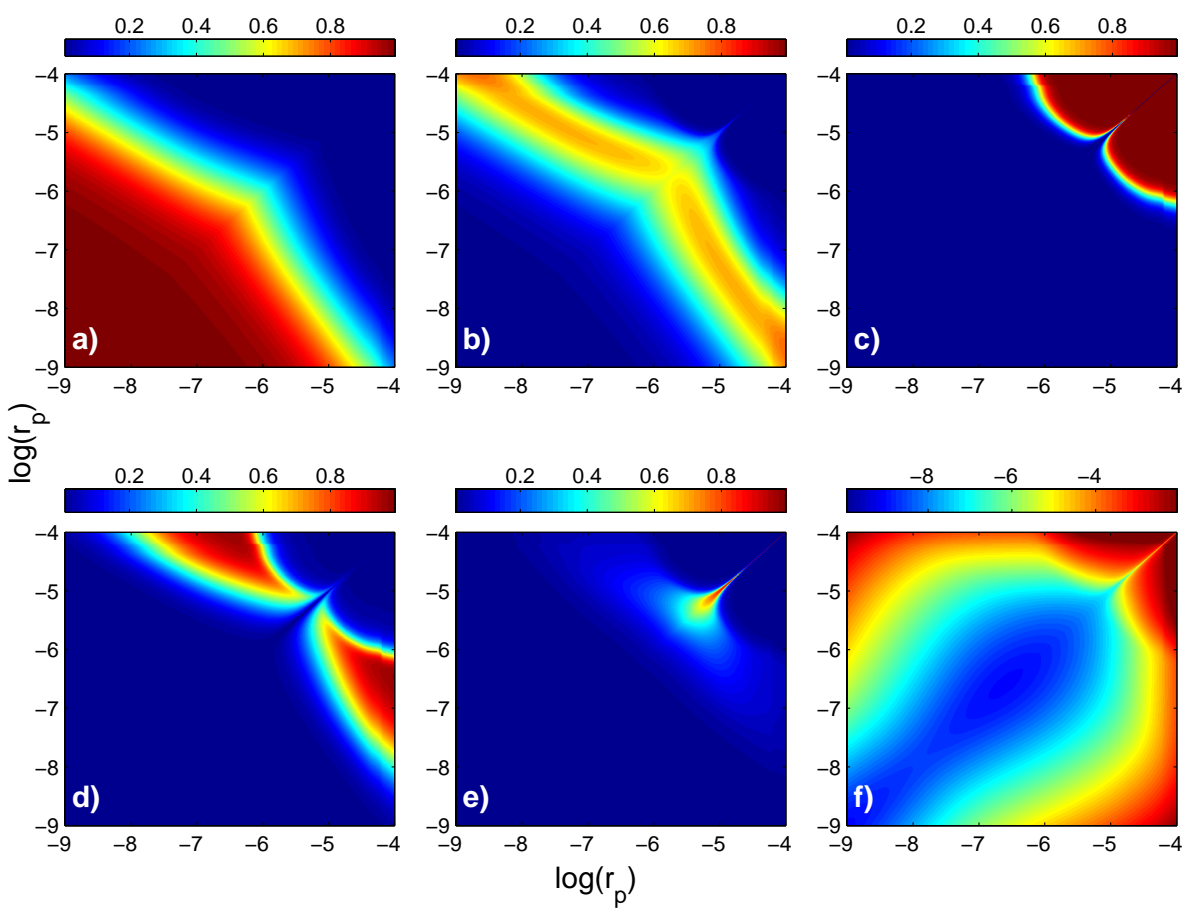

Fig. 2. Relative magnitude ( $K_{i} / K_{\text {tot }}$, marked with color) of different coagulation kernels for different sized particles. Axes in figures are in logscale from $1 \mathrm{~nm}$ to $100 \mu \mathrm{m}$ with the logarithm (10 base) of radius presented. Different kernels are (a) Brownian coagulation $K_{B}$, (b) convective Brownian diffusion enhancement $K_{B E}$, (c) gravitational collection $K_{G}$, (d) turbulent inertia $K_{T I}$, and (e) turbulent shear $K_{T S}$. In (f) the logarithm (10 base) of the total coagulation kernel $\left(\mathrm{cm}^{3} \mathrm{~s}^{-1}\right)$ is presented.

The coagulation kernel consists of five different parts: Brownian coagulation $K_{B}$, gravitational collection $K_{G}$, convective Brownian diffusion enhancement $K_{B E}$, turbulent inertia $K_{T I}$, and turbulent shear $K_{T S}$. The first one is caused by random movement of particles in the carrier gas. The second one is caused by different gravitational settling velocities. The third one, caused by eddies forming behind the large particles falling in the gas, is not as well established (Pruppacher and Klett, 1997). These eddies enhance the diffusion of smaller particles onto the surface of falling particle. The fourth and the fifth kernels are caused by turbulence in the air, which will lead to collisions due to inability of particles to follow the eddies due to their inertia and due to the different velocities between particles because of turbulent shear. In this study we use expressions for the individual coagulation kernels as e.g. in Jacobson (1999) and estimate the total coagulation kernel as (Saffman and Turner, 1956)

$K_{t o t}=K_{B}+K_{B E}+\left(K_{G}^{2}+K_{T I}^{2}+K_{T S}^{2}\right)^{1 / 2}$.

During coagulation, the mass of the coagulating particles is moved to the size class corresponding to the size of formed particle. It is assumed that the particles are internally mixed and the mixing within a size class occurs instantaneously after the coagulation. Because of the moving sections, the size class in which the formed particle is placed, is determined during the simulation continuously. Figure 1 illustrates how the size class in which the new particle (formed in the collision between two particles from section $i$ ) is placed can change during a cloud formation. In below cloud conditions, the new particle is placed to section $i+2$ but in cloud it is placed to section $i+4$. This change is due to narrowing of cloud droplet distribution due to a rapid condensation of water. This will produce inaccuracies in the dry size of droplets, because droplets in section $i+4$ are more concentrated than those formed through collision. What happens is that after evaporation, the mean size of particles in section $i+4$ can be smaller than the mean size in section $i+3$. This is a problem if cloud formation-evaporation cycles are studied. To avoid this, the cloud droplets formed in the collisions between two droplets are moved to a new cloud droplet distribution if the "target classes" based on wet and dry sizes differ considerably. The number of bins reserved for these cloud droplets is varied between 20 and 30 in the simulations done. A higher number increases accuracy, but it also increases computational burden, and thus the number chosen is a compromise. After evaporation, particles from these bins are placed back to the original size distribution according to their dry size. This decreases the abovementioned error and is important when cloud cycles are studied. 

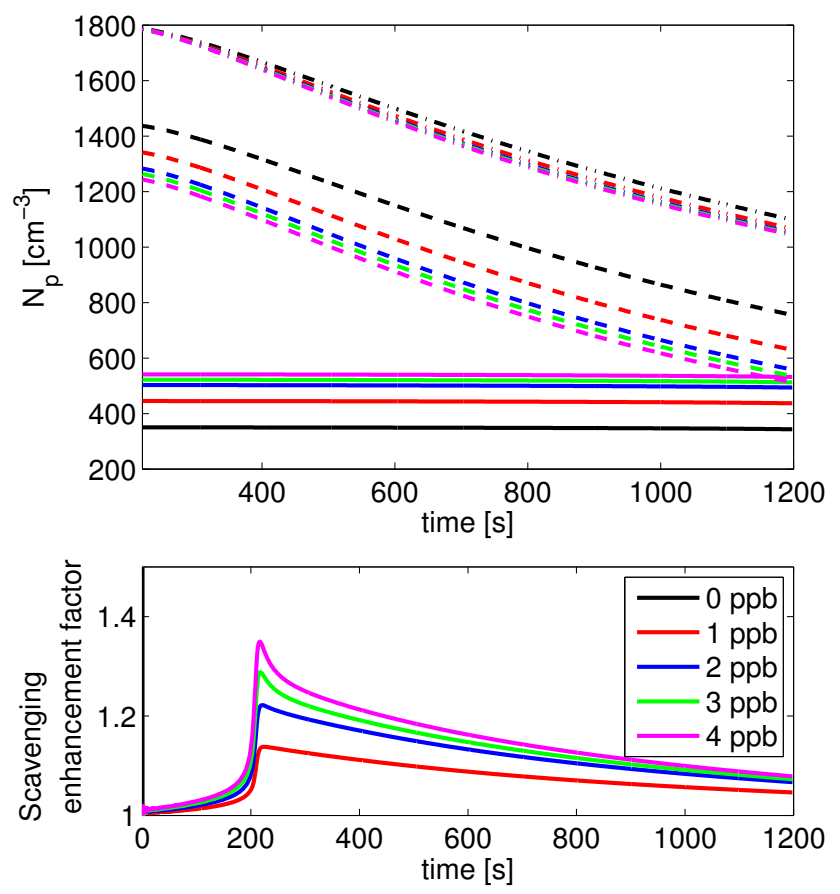

Fig. 3. Upper: Number of cloud droplets (solid lines) and interstitial particles (dashed lines), and the total number (dash-totted lines) as a function of time during the simulation for five different $\mathrm{HNO}_{3}$ concentrations (different colors). Concentrations are scaled to initial conditions to remove the effect of adiabatic expansion. Lower: Enhancement factor in the scavenged fraction due to $\mathrm{HNO}_{3}$ as a function of time. The initial size distribution is continental from Table 1.

\section{Results}

\subsection{Different coagulation kernels}

Figure 2 shows how the different coagulation kernels affect the coagulation between particles of different sizes. The dissipation rate of turbulent energy is assumed to be $10 \mathrm{~cm}^{2} \mathrm{~s}^{-3}$. In the atmosphere it typically varies between $3 \mathrm{~cm}^{2} \mathrm{~s}^{-3}$ and $2000 \mathrm{~cm}^{2} \mathrm{~s}^{-3}$ (Pruppacher and Klett, 1997) depending on the conditions. Typically, the values are low in cloud free conditions and high in strong cumulus convection. It can be seen from Fig. 2 that Brownian and Brownian diffusion enhancement are the only important coagulation mechanisms for small particles. In the early stages of a cloud, droplets coagulate due to Brownian enhancement and due to both turbulent mechanisms. If the droplet distribution is narrow, the enhanced Brownian coagulation by the wake eddies and turbulent shear coagulation broaden the distribution and make also turbulent inertia efficient as a coagulation mechanism. Gravitational collection is important only for droplets larger than $10 \mu \mathrm{m}$ in radius.

\subsection{Coagulation scavenging}

$\mathrm{HNO}_{3}$ increases CDNC leading to a decrease in the mean size of the droplets. This also affects the coagulation scavenging of interstitial particles. The total cloud droplet surface area increases and so the Brownian coagulation rate increases. On the other hand, both gravitational and turbulence induced coagulation slow down. Figure 3 shows the effect of $\mathrm{HNO}_{3}$ on the number of interstitial particles and cloud droplet number concentration. The aerosol particle size distribution (discretized into 200 size classes) is the continental distribution presented in Table 1 , the updraft velocity is $1.0 \mathrm{~m} / \mathrm{s}$, the initial temperature is $285 \mathrm{~K}$ and the initial pressure is 900 mbar. Sulfuric acid production is not included in these simulations. With these values the water saturation ratio exceeds unity approximately $200 \mathrm{~s}$ into the simulation. Figure 3 also shows that the increased cloud droplet number concentration due to the uptake of $\mathrm{HNO}_{3}$ enhances the coagulation scavenging. After $800 \mathrm{~s}$, the total number of aerosol particles is approximately $50 \mathrm{~cm}^{-3}$ lower in the case of $4 \mathrm{ppb}$ of $\mathrm{HNO}_{3}$ present compared to the $0 \mathrm{ppb}$ case. The reduction is mainly due to the decrease in the number concentration of particles with diameter around 20-30 nm (wet size in cloud). As can be seen from Fig. 4, particles smaller than $20 \mathrm{~nm}$ coagulate rapidly also when CDNC is smaller. From Fig. 3 it can be also seen that the relative effect of $\mathrm{HNO}_{3}$ condensation on coagulation scavenging is the highest right after cloud formation. During the cloud formation the total surface area of cloud droplets is clearly increased due to condensed $\mathrm{HNO}_{3}$, hence the reduction of small aerosol particles due to Brownian coagulation is more effective. When time goes on, the relative enhancement in the total surface area of cloud droplets decreases, and most of the smallest aerosol particles are already scavenged, leading to decrease in the relative effect of $\mathrm{HNO}_{3}$ condensation on coagulation scavenging. Decrease in the total number concentration is highest after $900 \mathrm{~s}$ into the simulation and after that the differences in the total number concentration decreases.

The length of the simulation is chosen to be short enough to prevent effective droplet-droplet coalescence due to gravitational coagulation. In the $0 \mathrm{ppb}$ case the decrease of CDNC due to coagulation is $6 \mathrm{~cm}^{-3}$. In the $4 \mathrm{ppb}$ case the decrease is $8.6 \mathrm{~cm}^{-3}$, and so the relative decrease is not affected considerably by $\mathrm{HNO}_{3}$.

Concerning the multiple modes seen clearly in Fig. 4f, the question arises whether they correspond to reality or are a numerical artefact. With a narrow, stagnant (nongrowing) droplet population with diameters centered around $D_{0}$, coalescence evidently produces peaks to the size distribution. Droplets with diameter close to $2^{1 / 3} D_{0}$ appear first, then droplets with $D$ approximately $3^{1 / 3} D_{0}$, etc. Condensational growth could, however, effectively smear out such peaks, depending on the relative growth rates. Diffusional growth law dictates that the diameter growth rate is proportional to $D^{-1}$. Let us consider an example: A 
(a)

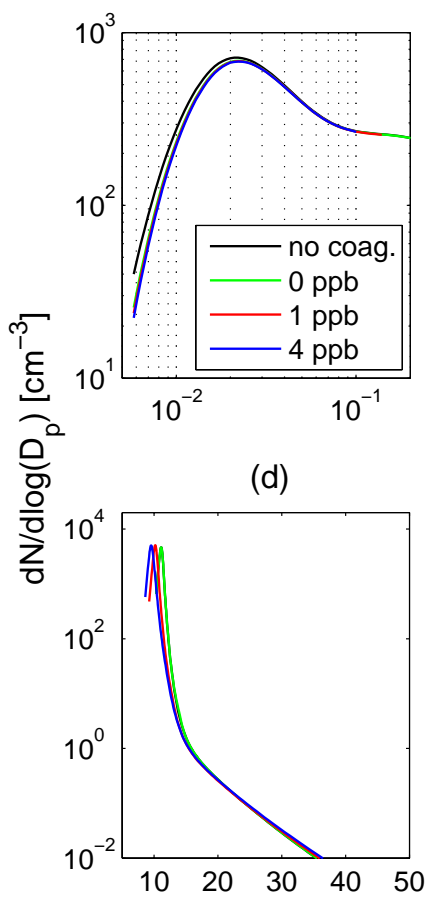

(b)

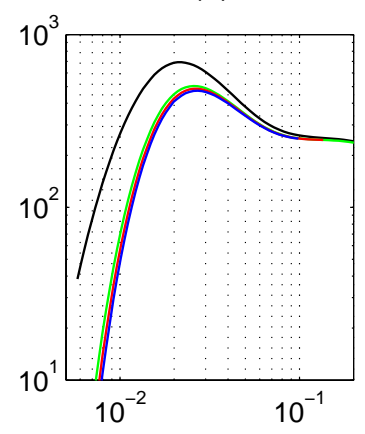

(e)

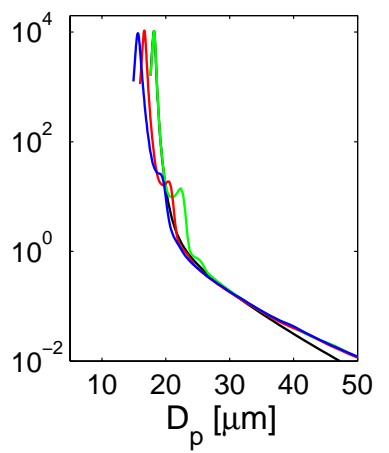

(c)

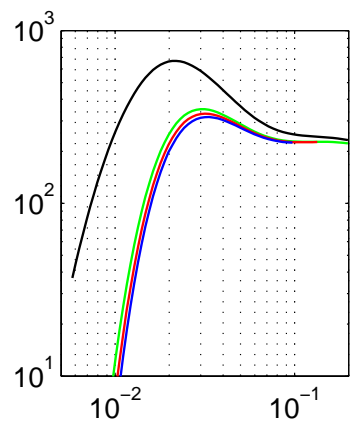

(f)

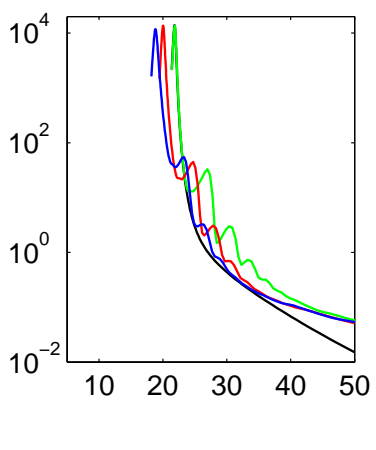

Fig. 4. Interstitial aerosol particles (a, b, c) and cloud droplets (d, e, f) $100 \mathrm{~s}(\mathrm{a}, \mathrm{d}), 500 \mathrm{~s}(\mathrm{~b}, \mathrm{e})$ and $900 \mathrm{~s}(\mathrm{c}, \mathrm{f})$ after cloud formation. For reference, curves without coagulation $\left(0 \mathrm{ppb}\right.$ of $\left.\mathrm{HNO}_{3}\right)$ and with coagulation for $0 \mathrm{ppb}, 1 \mathrm{ppb}$ and 4 ppb of $\mathrm{HNO}_{3}$ are presented. The initial size distribution is continental from Table 1.

monodisperse droplet population with diameter $D_{0}$ starts growing at $t=0$ until it has doubled its size $\left(2 D_{0}\right)$ at time $t_{2}$. At $t=0$, coalesced droplets are produced with diameter $2^{1 / 3} D_{0}\left(=1.26 D_{0}\right)$, which also start growing. It can easily be shown that their size at time $t_{2}$ is $2.14 D_{0}$. At the same time, the primary droplets (with diameter $2 D_{0}$ ) coagulate with themselves, producing droplets with diameter $2^{1 / 3} 2 D 0=2.52 D_{0}$. Thus, in our example we have at time $t_{0}$ primary droplets at $D_{0}$ and coalesced droplets at $1.26 D_{0}$, while at time $t_{2}$ we have primary droplets at $2 D_{0}$ and coalesced droplets between $2.14 D_{0}$ and $2.52 D_{0}$. The coalesced droplets are thus distributed within a relatively narrow size range. Similarly, in our cloud model runs coalescence produces peaks which get wider as the runs progress, and we have no reason to consider them as numerical artefacts. These peaks can be avoided only by decreasing the size resolution of the model to be worse than the size difference between the droplets formed through coalescence.

\subsection{Sulfuric acid production}

Sulfuric acid production increases the water soluble mass in cloud droplets. This affects both the direct and the indirect aerosol effect. Aerosol mass increases mainly in the accumulation mode, in which the particles are efficient scatterers and so the direct effect may be considerable in some situations (Yuskiewicz et al., 1999; Hegg et al., 1996). Changes in aerosol particle size distribution also affect the formation of cloud droplets during the next cloud cycle. Depending on the conditions, the number concentration of cloud droplets can either increase or decrease (Feingold and Kreidenweis, 2000).

\subsubsection{Implications for radiative effects}

In Fig. 5, the effect of $\mathrm{HNO}_{3}$ on continental aerosol size distributions after one cloud cycle is presented in the case of $\mathrm{H}_{2} \mathrm{O}_{2}$ induced $\mathrm{H}_{2} \mathrm{SO}_{4}$ production. In this simulation initial $R H$ is $90 \%$, updraft/downdraft velocity is $1.0 \mathrm{~m} / \mathrm{s}$ and length of both is $600 \mathrm{~s}$. The initial concentration of $\mathrm{SO}_{2}$ and $\mathrm{H}_{2} \mathrm{O}_{2}$ are $2 \mathrm{ppb}$ and $0.5 \mathrm{ppb}$, respectively. Due to $1 \mathrm{ppb}$ of $\mathrm{HNO}_{3}$, $98 \mathrm{~cm}^{-3}$ more cloud droplets form. Although the condensation of $\mathrm{HNO}_{3}$ increases the acidity of cloud droplets, the amount of $\mathrm{H}_{2} \mathrm{SO}_{4}$ produced is independent of the $\mathrm{HNO}_{3}$ concentration when $\mathrm{SO}_{2}$ is oxidized by $\mathrm{H}_{2} \mathrm{O}_{2}$. The diameters of the smallest activated particles grow more than by a factor of 3 and the number concentration of particles larger than $200 \mathrm{~nm}$ in diameter increases. This could be significant, because the most efficient scatterers are particles with diameters between $200 \mathrm{~nm}$ and $800 \mathrm{~nm}$ (Yuskiewicz et al., 1999). 


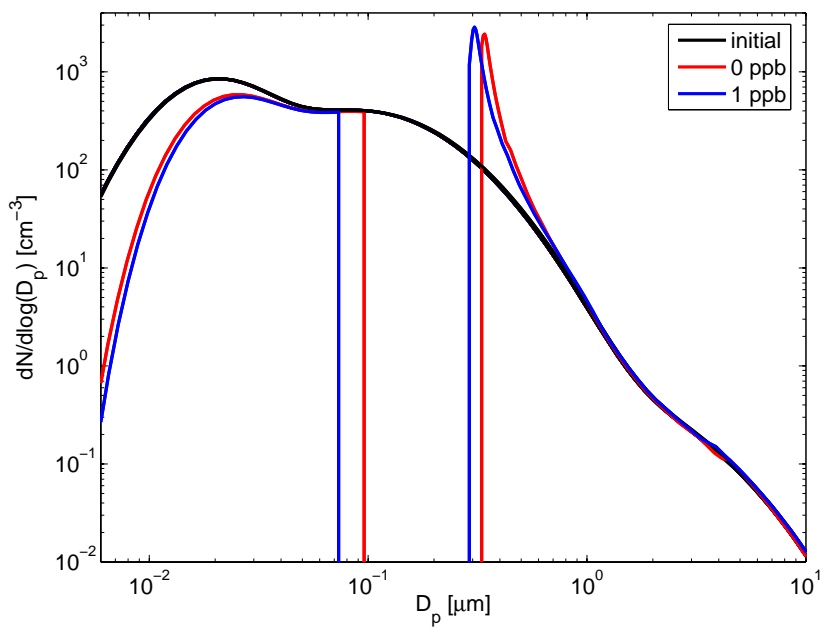

Fig. 5. Aerosol particle size distribution before and after one cloud cycle at $\mathrm{RH}$ of $90 \%$, for two different $\mathrm{HNO}_{3}$ concentrations.

To test this effect the total light scattering was calculated according to Seinfeld and Pandis (1998) and the extinction coefficient according to Bohren and Huffman (1983). The refractive index was assumed constant at $m=1.5-0.03 i$ for all particles. In the case presented in Fig. 5, the total light scattering increases from $3.5 \times 10^{-5} \mathrm{~m}^{-1}\left(3.8 \times 10^{-5} \mathrm{~m}^{-1}\right.$ after initial equilibration with $1 \mathrm{ppb}$ of $\mathrm{HNO}_{3}$ ) to $9.5 \times 10^{-5} \mathrm{~m}^{-1}$ when there is no $\mathrm{HNO}_{3}$ in the gas and to $9.0 \times 10^{-5} \mathrm{~m}^{-1}$ with $1 \mathrm{ppb}$ of $\mathrm{HNO}_{3}$. Relative change in the light scattering is quite high, but the change in the absolute value is of the same order as values presented in Yuskiewicz et al. (1999).

With other updraft velocities and/or aerosol distributions the highest sulfate production occurs in particles with different initial sizes. In Table 2 we have collected results of changes in light scattering with different updraft velocities and distributions (presented in Table 1). In simulations with different velocities the time the air parcel stays in cloud is kept constant. Thus in the simulations presented, the cloud liquid water content increases as the velocity increases and so more sulfuric acid is produced. This increases the change in light scattering. On the other hand, increased velocity increases CDNC and so the amount of sulfuric acid produced per droplet is smaller. This decreases the change in light scattering. The same occurs also when the cloud droplet number concentration is increased by $\mathrm{HNO}_{3}$. It can be seen that in continental and urban cases the change in light scattering is smaller with $\mathrm{HNO}_{3}$, and in marine cases $\mathrm{HNO}_{3}$ does not effect the change in light scattering. These differences are due to very different aerosol particle size distributions. It can be seen that the biggest change in light scattering occurs with the urban distribution. This is due to the lack of big particles in the distribution used. The number concentration of particles larger than $300 \mathrm{~nm}$ in diameter in the initial distribution is less than $7 \mathrm{~cm}^{-1}$ and after cloud processing, the corresponding concentration is close to $200 \mathrm{~cm}^{-1}$ in the $1 \mathrm{~m} / \mathrm{s}$
Table 2. Change (\%) in the total light scattering due to $\mathrm{H}_{2} \mathrm{SO}_{4}$ production. $h$ is the height of updraft above the $S=1$ level.

\begin{tabular}{lccc}
\hline CONTINENTAL & $h(\mathrm{~m})$ & $C_{\mathrm{HNO}_{3}}=1 \mathrm{ppt}$ & $C_{\mathrm{HNO}_{3}}=1 \mathrm{ppb}$ \\
\hline $0.1 \mathrm{~m} / \mathrm{s}$ & 30 & 42.3 & 32.3 \\
$0.5 \mathrm{~m} / \mathrm{s}$ & 150 & 111.8 & 86.1 \\
$1.0 \mathrm{~m} / \mathrm{s}$ & 300 & 132.1 & 102.7 \\
\hline MARINE & & $C_{\mathrm{HNO}_{3}}=1 \mathrm{ppt}$ & $C_{\mathrm{HNO}_{3}}=1 \mathrm{ppb}$ \\
\hline $0.1 \mathrm{~m} / \mathrm{s}$ & 30 & 11.5 & 11.7 \\
$0.5 \mathrm{~m} / \mathrm{s}$ & 150 & 47.6 & 47.4 \\
$1.0 \mathrm{~m} / \mathrm{s}$ & 300 & 61.0 & 60.7 \\
\hline RURAL & & $C_{\mathrm{HNO}_{3}}=1 \mathrm{ppt}$ & $C_{\mathrm{HNO}_{3}}=1 \mathrm{ppb}$ \\
\hline $0.1 \mathrm{~m} / \mathrm{s}$ & 30 & 153.6 & 110.2 \\
$0.5 \mathrm{~m} / \mathrm{s}$ & 150 & 273.7 & 203.3 \\
$1.0 \mathrm{~m} / \mathrm{s}$ & 300 & 273.6 & 201.8 \\
\hline
\end{tabular}

case. In the marine case, there is a large number of very big particles, and so the total light scattering before cloud processing is higher than with other distributions. It should be also noted, that because of a large alkaline mode, the effect of $\mathrm{HNO}_{3}$ on $\mathrm{CDNC}$ is low although the used $\mathrm{HNO}_{3}$ concentration of $1 \mathrm{ppb}$ is very high for marine conditions.

\subsubsection{Implications for cloud droplet number concentration}

Formation of sulfuric acid increases the water soluble mass in cloud droplets, which can lead to bimodality in the aerosol particle size distribution after the evaporation of cloud. Particles will activate to cloud droplets more easily during the next cloud cycle because of increased mass. However, at the same time, increased mass will decrease the maximum supersaturation, making the activation of particles not processed more unlikely. Therefore, if the updraft velocity is the same for every cycle, the number concentration of cloud droplets stays very likely unchanged. To study possible differences between the cases with and without $\mathrm{HNO}_{3}$ and with and without sulfuric acid production a set of model simulations was done by varying the updraft velocities between the different cycles. Particle distribution is the continental aerosol particle distribution from Table 1 and the initial concentration of $\mathrm{SO}_{2}$ and $\mathrm{H}_{2} \mathrm{O}_{2}$ are $2 \mathrm{ppb}$ and $0.5 \mathrm{ppb}$, respectively. For simplicity, coagulation is not included in these simulations.

We first consider a situation in which the updraft velocity is lower during the first cycle than during the following cycles. The first cycle produces $\mathrm{H}_{2} \mathrm{SO}_{4}$ to droplets that will activate in any case during the next cycles. This causes the maximum supersaturation to decrease during the following cycles, and the increased velocity does not increase the number concentration of activated particles as much as in the case without $\mathrm{H}_{2} \mathrm{SO}_{4}$-production. Results for the example cases 
Table 3. Number of cloud droplets $\left(\mathrm{cm}^{-3}\right)$ during different cloud cycles. Values in parenthesis are without $\mathrm{H}_{2} \mathrm{SO}_{4}$-production.

\begin{tabular}{cccc}
\hline$C_{\mathrm{HNO}_{3}}$ /velocity & 0.1 & 0.2 & 1.0 \\
\hline $\begin{array}{l}0 \mathrm{ppb} \\
1 \mathrm{ppb}\end{array}$ & $118(118)$ & $133(166)$ & $337(337)$ \\
\hline$C_{\mathrm{HNO} 3} /$ velocity & 1.0 & $184(245)$ & $436(436)$ \\
\hline $0 \mathrm{ppb}$ & $337(337)$ & $337(166)$ & $267(118)$ \\
$1 \mathrm{ppb}$ & $436(436)$ & $387(245)$ & $245(149)$ \\
\hline
\end{tabular}

are presented in Table 3. It is seen that if the velocity of the first cloud cycle is $0.1 \mathrm{~m} / \mathrm{s}, \mathrm{CDNC}$ is clearly decreased during the next cloud cycle when compared to simulations done without $\mathrm{H}_{2} \mathrm{SO}_{4}$ chemistry. In the third cycle the velocity is increased to $1.0 \mathrm{~m} / \mathrm{s}$ and the maximum saturation depression is not strong enough to decrease CDNC. In this simulation the height of the cloud is close to $100 \mathrm{~m}$ and thus almost all $\mathrm{H}_{2} \mathrm{O}_{2}$ is depleted during the first cycle.

If the updraft velocity of the first cycle is faster than that of the next cycles, the activation becomes easier due to sulfuric acid production. This can be seen from the bottom example in Table 3. In this case the cloud height is close to $150 \mathrm{~m}$ and $150 \mathrm{ppt}$ of $\mathrm{H}_{2} \mathrm{SO}_{4}$ is produced on the first cycle and $280 \mathrm{ppt}$ during the second cycle. It can be seen that on the second cycle CDNC is clearly increased especially in the case without $\mathrm{HNO}_{3}$ when compared to simulations done without $\mathrm{H}_{2} \mathrm{SO}_{4}$ chemistry. On the third cycle, when the updraft velocity is $1 \mathrm{~m} / \mathrm{s}, \mathrm{CDNC}$ is $267 \mathrm{~cm}^{-3}$ without $\mathrm{HNO}_{3}$ and $245 \mathrm{~cm}^{-3}$ with $1 \mathrm{ppb}$ of $\mathrm{HNO}_{3}$. This result is rather surprising, because it is expected that during a single updraft $\mathrm{HNO}_{3}$ increases CDNC. What happens in this case is that due to a different number of cloud droplets during previous cloud cycles, the initial aerosol size distributions for the third cycle differ in cases with and without $\mathrm{HNO}_{3}$ so much, that the number of cloud droplets becomes lower in the former case. This can be seen from Fig. 6, where the dry size of particles is presented for a subset of bins used. On the third cycle activation occurs between bins 49 and 50, when there is no $\mathrm{HNO}_{3}$ and between bins 50 and 51 with $1 \mathrm{ppb}$ of $\mathrm{HNO}_{3}$. It can be seen, that around these bins, the dry size is larger without $\mathrm{HNO}_{3}$ than with $\mathrm{HNO}_{3}$. Also the acidity of these bins increases during cloud cycles and this leads to decreased amount of condensed $\mathrm{HNO}_{3}$ during following cloud cycles further decreasing the effect of $\mathrm{HNO}_{3}$ on cloud droplet number concentration.

Worth mentioning in Table 3 is that the relative effect of $\mathrm{HNO}_{3}$ on cloud droplet number concentration is higher with the $1.0 \mathrm{~m} / \mathrm{s}$ (29\% increase) than with the $0.1 \mathrm{~m} / \mathrm{s}(26 \%$ increase) updraft velocity. Usually the opposite is expected (e.g. Nenes et al., 2002; Xue and Feingold, 2004). What must be kept in mind, however, that in our model a whole bin activates at a time and this produces some inaccuracy to

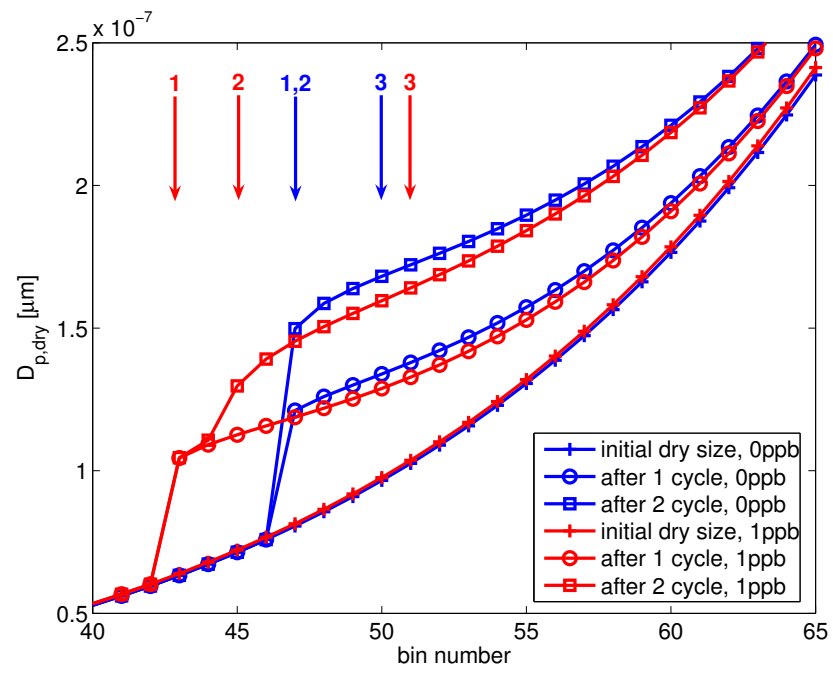

Fig. 6. Aerosol particle dry size as a function of a bin number before cloud cycles and after one and two cloud cycles with $1 \mathrm{ppb}$ of $\mathrm{HNO}_{3}$ and without $\mathrm{HNO}_{3}$. The smallest bin activated during different cloud cycles is marked with arrow and the number above arrow denotes the number of cloud cycle.

the results, and thus the increase in the size resolution can change the result slightly. However, in this case the relative effect is almost similar also with the better resolution. The reason for this unexpected result is the width of the mode containing most of the activating particles. In this case the geometric standard deviation is 2.16. This increases the activated fraction without $\mathrm{HNO}_{3}$ and decreases the effect of $\mathrm{HNO}_{3}$ compared to more narrow mode. With the higher updraft velocity the number of cloud droplets formed is not so dependent on the standard deviation as with the low updraft velocity.

\section{Conclusions}

In previous studies it has been shown that $\mathrm{HNO}_{3}$ increases the number concentration of cloud droplets. In this study we take one step further and study how the increased droplet number concentration affects the cloud processing of the aerosol particle distribution. This is done with an air parcel model including condensation, coagulation and liquid phase chemistry. The coagulation kernel includes individual kernels for Brownian coagulation, convective Brownian diffusion enhancement, gravitational collection, turbulent inertia, and turbulent shear. It was found that both Brownian coagulation mechanisms are important for interstitial aerosol particle scavenging and that turbulent shear and convective Brownian diffusion enhancement are the most important mechanisms for drop-drop collisions as long as cloud droplet distribution is narrow and gravitational collection is not efficient. 
The increased cloud droplet number concentration due to $\mathrm{HNO}_{3}$ was shown to speed up the scavenging of interstitial particles. This is due to an increased total surface area of cloud droplets which leads to a more effective scavenging through Brownian and convective Brownian diffusion enhancement coagulation mechanisms. The relative increase in the scavenged fraction is highest in the early stages of cloud and decreases as a function of cloud height.

Due to increased CDNC, sulfuric acid production occurs in smaller particles, but the amount of acid produced decreases if ozone is the only oxidant available. However, when there is $\mathrm{H}_{2} \mathrm{O}_{2}$ in the system, the amount of sulfuric acid produced is independent of the $\mathrm{HNO}_{3}$ concentration, and so the number of particles growing due to cloud processing is higher with $\mathrm{HNO}_{3}$ than without $\mathrm{HNO}_{3}$. This leads to smaller mass production per particle and so the changes in the radiative properties of aerosol particles are smaller with $\mathrm{HNO}_{3}$ than without $\mathrm{HNO}_{3}$.

How the sulfuric acid production affects CDNC on the cloud cycles following the first cycle, is dependent on the updraft velocity and initial aerosol particle distribution. Although the condensation of $\mathrm{HNO}_{3}$ increases the number of cloud droplets during a single updraft, it is possible that presence of the $\mathrm{HNO}_{3}$ can actually decrease the cloud droplet number concentration after several cloud cycles when also sulfuric acid production is taken into account, compared to a case without $\mathrm{HNO}_{3}$. This can happen when the updraft velocity decreases after the first cloud cycle. Although only one set of simulations is presented, it is clear that this kind of coupling makes it more difficult to conclude what is the overall effect of condensable trace gases on global radiative forcing. To explore that, proper $2 \mathrm{D}$ or $3 \mathrm{D}$ simulations including the effect of water soluble gases on cloud droplet formation and also cloud processing are needed.

Acknowledgements. This study was supported by the Academy of Finland (project number 201052) and the Center-of-Excellence program.

Edited by: M. G. Lawrence

\section{References}

Bohren, C. F. and Huffman, D. R.: Absorption and scattering of light by small particles, John Wiley \& Sons inc., 1983.

Bower, K. N. and Choularton, T. W.: Cloud processing of the cloud condensation nucleus spectrum and its climatological consequences, Q. J. R. Meteorol. Soc., 119, 655-679, 1993.

Bromley, L. A.: Thermodynamic properties of strong electrolytes in aqueous solutions, AIChE J., 19, 313-320, 1973.

Feingold, G. and Kreidenweis, S. M.: Does cloud processing of aerosol enhance droplet concentrations?, J. Geophys. Res., 105, 24351-24361, 2000.
Hegg, D. A., Majeed, R., Yuen, P. F., Baker, M. B., and Larson, T. V.: The impacts of $\mathrm{SO}_{2}$ oxidation in cloud drops and in haze particles on aerosol light scattering and CCN activity, Geophys. Res. Lett., 23, 2613-2616, 1996.

Hegg, D. A.: Impact of gas-phase $\mathrm{HNO}_{3}$ and $\mathrm{NH}_{3}$ on microphysical processes in atmospheric clouds, Geophys. Res. Lett., 27, 22012204, 2000.

Hegg, D. A., Covert, D. S., Jonsson, H., Khelif, D., and Friehe, C. A.: Observations of the impact of cloud processing on aerosol light-scattering efficiency, Tellus B, 56 (3), 285-293, 2004.

Hoppel, W. A., Frick, G. M., Fitzgerald, J. W., and Larson, R. E.: Marine boundary layer measurements of new particle formation and the effects nonprecipitating clouds have on aerosol size distribution, J. Geophys. Res., 99, 14 443-14 459, 1994.

Jacobson, M. Z.: Studying the effects of calcium and magnesium on size-distributed nitrate and ammonium with EQUISOLV II, Atmos. Environ., 33, 3635-3649, 1999.

Jacobson, M. Z.: Fundamentals of atmospheric modeling, Cambridge University Press, Cambridge, 1999.

Kokkola, H.: Model studies on the evolution of fogs and clouds in the presence of semi-volatile gases, $\mathrm{PhD}$ thesis, University of Kuopio, Department of applied physics, Report Series in Aerosol Science, 61, 2003.

Kokkola, H., Romakkaniemi, S., and Laaksonen, A.: Köhler theory for polydisperse droplet populations in the presence of a soluble trace gas and an application to stratospheric STS droplet growth, Atmos. Chem. Phys., 3, 2139-2146, 2003.

Kulmala, M., Laaksonen, A., Korhonen, P., Vesala, T., Ahonen, T., and Barrett, J. C.: The effect of atmospheric nitric acid vapor on cloud condensation nucleus activation, J. Geophys. Res., 98, 22 949-22 958, 1993.

Nenes, A., Charlson R. J., Facchini M. C., Kulmala, M., Laaksonen, A., and Seinfeld, J. H.: Can chemical effects on cloud droplet number rival the first indirect effect?, Geophys. Res. Lett., 29, doi:10.1029/2002GL015295, 2002.

Pruppacher, H. R. and Klett, J. D.: Microphysics of Clouds and Precipitation, Kluwer Academic Publishers, Netherlands, 1997.

Roelofs, G.-J. and Jongen, S.: A model study of the influence of aerosol size and chemical properties on precipitation formation in warm clouds, J. Geophys. Res., 109, D22201, doi:10.1029/2004JD004779, 2004.

Romakkaniemi, S., Kokkola, H., and Laaksonen, A.: Parameterization of the nitric acid effect on CCN activation, Atmos. Chem. Phys., 5, 879-885, 2005.

Saffman, P. G. and Turner, J. S.: On the collision of drops in turbulent clouds, J. Fluid Mech., 1, 16-30, 1956.

Seinfeld, J. H. and Pandis, S. N.: Atmospheric Chemistry and Physics, From air pollution to climate change, Wiley, New York, 1998.

Xue, H. and Feingold, G.: A modeling study of the effect of nitric acid on cloud properties, J. Geophys. Res., 109, D18204, doi:10.1029/2004JD004750, 2004.

Yuskiewicz, B. A., Stratmann, F., Birmili, W., Wiedensohler, A., Swietlicki, E., Berg, O., and Zhou, J.: The effects of in-cloud mass production on atmospheric light scatter, Atmos. Res., 50, 265-288, 1999. 